\section{Stomata morphological traits in two different genotypes of Populus nigra L.}

\author{
Giuseppe Russo $^{(1)}$, Paolo De Angelis ${ }^{(2)}$, James E Mickle ${ }^{(3)}$, Maria Rosaria \\ Barone Lumaga ${ }^{(4)}$
}

Populus nigra L. (black poplar) possesses amphistomatic leaves, with large (giant) and normal sized stomata. The role of giant stomata in leaf development, and the consequences on stomatal density in adult leaves remains elusive. This paper describes the characteristics of ordinary and giant stomata in leaves of two black poplar genotypes (58-861 with large leaves from northern Italy, and Poli with small leaves from southern Italy). Stomatal traits in both genotypes were studied using light microscopy on mature leaf adaxial and abaxial epidermal impressions. Moreover, scanning electron microscopy was applied to study giant and normal stomata in early, young, and mature leaves. Leaf abaxial surfaces in the two genotypes revealed variable sizes and patterns of stomata related to differences in intrinsic water use efficiency $\left(W_{i}\right)$. These observations provided evidence of different stomatal types in mature black poplar leaves, and new information regarding the presence and potential role of giant stomata in black poplar leaves.

Keywords: Giant Stomata, Poplar Clones, Genotypes, Populus, SEM

\section{Introduction}

Giant stomata (GS), as the name implies, are distinct from normal-sized stomata primarily due to size. In a treatise on the anatomy of dicotyledons, Metcalfe \& Chalk (1979) described large stomata of approximately $40 \mu \mathrm{m}$ in relatively few families. Shiraishi et al. (1975) reported structures in Satsuma Mandarin (Citrus unshiu Marc) similar to large-sized stomata, surrounded by a number of normal-sized stomata on juvenile leaves immediately after full leaf expansion. The giant type stomata observed in C. unshiu were consistent with GS examined and characterized by Sitholey \& Pandey (1971) and Stace (1965) in different taxa.

Electron microscopy studies on subfossil Holocene Salix herbacea L. (Salicaceae) samples in Sweden suggested the presence of GS (Rundgren \& Beerling 1999). Finally, Pautov (2009) reported an eterostomatal or- ganization in Populus tremula, with three stomatal types, i.e., paracitic, laterocitic, and intermediate anamo-paracytic.

Poplars (Populus spp.) are the fastest growing tree in temperate latitudes in Europe and North America (Marron et al. 2006) when raised under short rotation intensive culture conditions. Poplar is considered a model system for plant biology. P. tricocar$p a$ is the first tree genome to be fully sequenced, and is now of high quality and relatively contiguous. Therefore, the genus offers many possibilities to study questions not easily addressed by genera considered model plant systems, e.g., Arabidopsis thaliana (Jansson \& Douglas 2007). Stomatal traits have been widely studied in Populus, as these traits are a useful criterion for clone discrimination in the genus. In particular, a series of clones have been explored that confirm general poplar micromorphologic fea- $\square$ (1) Istituto di Biologia Agroambientale e Forestale (IBAF), Consiglio Nazionale delle Ricerche (CNR), Porano, TR (Italy); (2) Department for Innovation in Biological, Agro-food and Forest systems (DIBAF), Università della Tuscia, Viterbo (Italy); (3) Department of Plant and Microbial Biology, North Carolina State University, Box 7612, 27692-7612 Raleigh, NC (USA); (4) Dipartimento di Biologia, Orto Botanico, Università degli Studi Napoli “Federico II", Naples (Italy)

\section{@ Giuseppe Russo (giuseppe.russo@ibaf.cnr.it)}

Received: Aug 13, 2013 - Accepted: May 23, 2014

Citation: Russo G, De Angelis P, Mickle JE, Barone Lumaga MR, 2014. Stomata morphological traits in two different genotypes of Populus nigra L. iForest 8: 547-551 [online 2014-09-16] URL: http://www.sisef.it/iforest/contents/?id=ifor1104-007

Communicated by: Roberto Tognetti tures, including amphistomatic leaves, with evidence some stomatal traits change depending on environmental conditions (Al Afas et al. 2006), and in response to growing conditions (Woodward et al. 2002, Hermle et al. 2007, Di Baccio et al. 2010, Jaime et al. 2014). For example, in P. trichocarpa stomata were not found on the adaxial leaf surface when grown under field conditions, however low stomatal density was observed on the adaxial surface under glasshouse conditions (Ceulemans et al. 1988, Radoglou \& Jarvis 1990).

Despite frequent studies on stomata in poplar (Reich 1984, Ceulemans et al. 1988, Al Afas et al. 2006, Pearce et al. 2006, Cocozza et al. 2010, Woo 2010), reports of giant stomata in Populus remain equivocal.

Recently, interest in several poplar morphological and physiological traits has increased, with the aim of evaluating new breeding strategies for industrial applications (Kauter et al. 2003, Sebastiani et al. 2004). Additional knowledge of poplar stomata might support industrial objectives, since stomatal density has been demontrated to affect biomass production in different poplar clones (Al Afas et al. 2006).

\section{Materials and Methods}

\section{Plant material and growth conditions}

Observations were conducted using homogeneous $25 \mathrm{~cm}$ long woody stem cuttings obtained from two different $P$. nigra genotypes, 58-861 and Poli. The 58-861 genotype was the maternal parent from $\mathrm{Val} \mathrm{Ce}$ nischia (Torino, northern Italy - $597 \mathrm{~m}$ a.s.l., $45^{\circ} 09^{\prime} \mathrm{N}, 07^{\circ} 01^{\prime} \mathrm{E}$ ), and Poli was obtained from Policoro (Matera, southern Italy - $7 \mathrm{~m}$ a.s.1., $\left.40^{\circ} 09^{\prime} \mathrm{N}, 16^{\circ} 41^{\prime} \mathrm{E}\right)$.

Full-sib families of both genotypes were planted in April 2008 in an open field at Azienda Didattico Sperimentale "Nello Lupori" in Viterbo (Italy, $42^{\circ} 25^{\prime} \mathrm{N}, 12^{\circ} 05^{\prime} \mathrm{E}$ $309 \mathrm{~m}$ a.s.1.). The 0.1230 ha experimental site, considered a short rotation coppice, had alternating inter-row distances of $2 \mathrm{~m}$ and $0.75 \mathrm{~m}$ between plants in a single row. Soil was composed of sand $(57.5 \%)$, lime $(34.6 \%)$, and clay (7.9\%), with a $\mathrm{pH}$ of 7.1 . A randomized complete block design (five blocks) was arranged; each block included a group of $160 \mathrm{~F} 1$ clones, and two pairs of parental clones (two Poli and two 58-861 clones). A total number of 820 plants were cultivated in the entire plantation (frequency of 6666 plants ha ${ }^{-1}$ ). Due to edge effects, the two poplar rows on the outermost border were not included in the experimental design. The plantation was irrigated shortly after planting, and a third class herbicide with weed control measures was applied to obtain optimal field establishment. Average daily temperature and rainfall in the 2008 growing 
Fig. 1 - Populus nigra L. (A-D): genotype Poli; (E-F); genotype 58-861. (A): Light image from nail polish impression of the adaxial surface of early leaf showing deve-

loping stomata, bar $=20 \mu \mathrm{m}$. (B): SEM image of the adaxial surface of a young leaf showing trichomes and water stomata, bar $=$ $100 \mu \mathrm{m}$. (C): SEM image of the adaxial sur-

face of a mature leaf, bar $=100 \mu \mathrm{m}$. (D): SEM image of the abaxial surface of a mature leaf showing anomocytic giant stomata (GS), GS covered by wax (asterisk), paracytic normal stomata (NS), bar $=100 \mu \mathrm{m}$. (E): SEM image of the adaxial surface of a mature leaf, bar $=100 \mu \mathrm{m}$. (F): SEM image of the abaxial surface of a mature leaf showing GS frequently covered by wax plugs, bar $=100 \mu \mathrm{m}$.

season were respectively $22.89{ }^{\circ} \mathrm{C}$ and 14.4 $\mathrm{mm}$. Only parentals (10 Poli and 10 58-861 clones) were examined for observations.

\section{WUE measurements}

Complete leaf development was examined by observing leaves throughout the entire growing season (June - September 2008) in 30 -day intervals from different leaf generations. Selected leaves marked by small ribbons around the petiole were observed daily, beginning with a young $(\sim 4.8 \mathrm{~cm}$ in Poli and $\sim 5.6$ in $58-861$ ) to mature totally expanded leaf condition, following the Plastochron Index method (Erickson \& Michelini 1957). The same leaves were analyzed to obtain physiological measurements (assimilation and stomatal conductance) in the hours before dawn. Excised leaves were placed in water filled test tubes to avoid cavitation, protected in a portable freezer, and transported to the laboratory. A LI-6400 photosynthesis system (LICOR, Nebraska, USA)
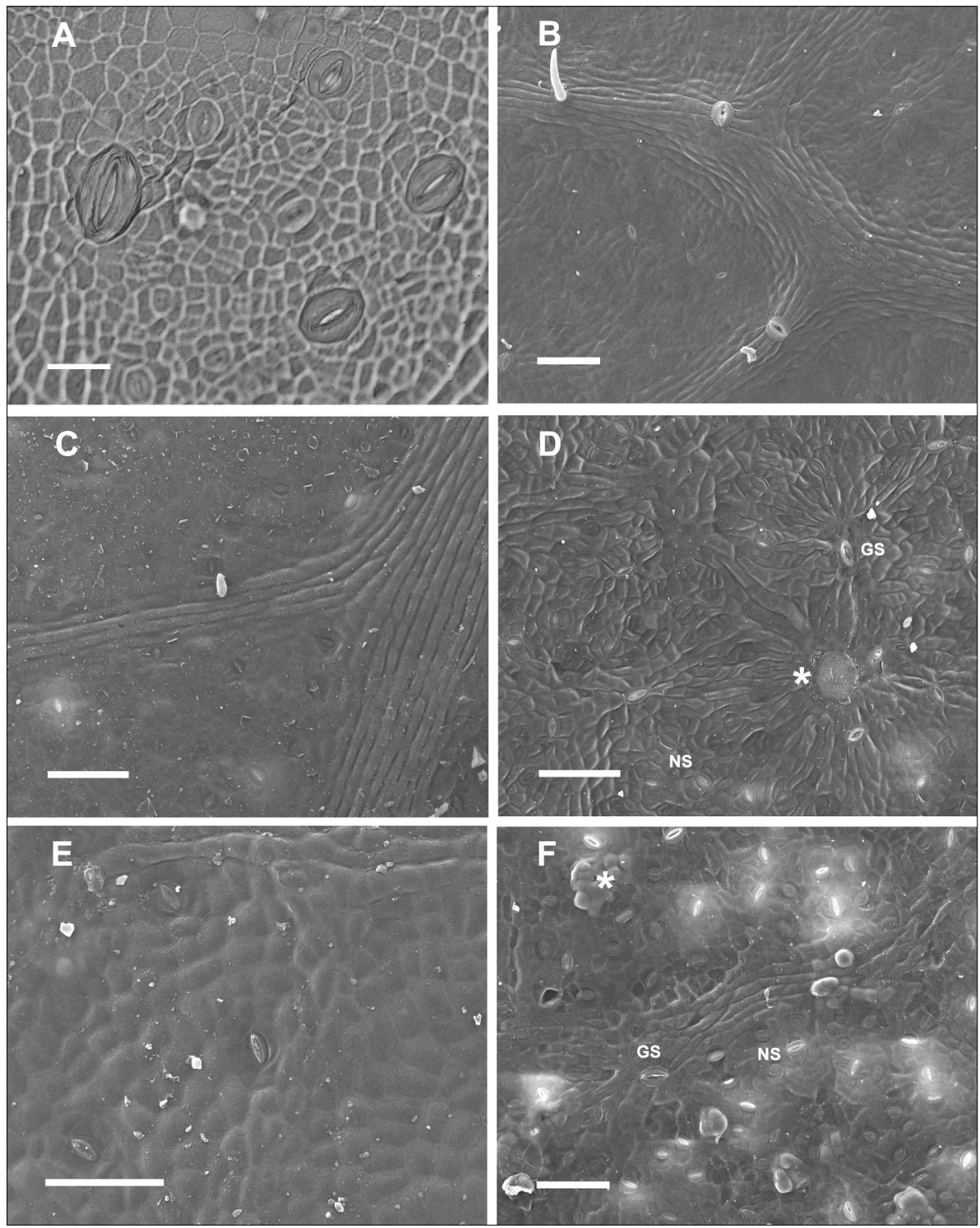

was programmed to register gas exchange at $380 \mathrm{ppm}$ relative to $\mathrm{CO}_{2}$ reference value. Intrinsic water use efficiency $\left(\mathrm{W}_{\mathrm{i}}\right)$ was determined as the ratio between assimilation $(A)$, expressed in $\mu \mathrm{mol} \mathrm{CO} \mathrm{CO}^{-2} \mathrm{~s}^{-1}$ and stomatal conductance $\left(g_{\mathrm{s}}\right)$, expressed in $\mathrm{mol} \mathrm{H}_{2} \mathrm{O} \mathrm{m}{ }^{-2}$ $\mathrm{s}^{-1}$.

\section{Statistical analyses}

Data management and statistical analyses were performed with SYSTAT ${ }^{\circledR} 12$ (Systat software, Chicago, IL) using 20 replicates of poplar genotypes (10 Poli and $10 \quad 58-861$ clones). A preliminary GS frequency analysis revealed a Poisson-shaped, zero-bounded distribution of counting data (x), which were therefore transformed as $\sqrt{\mathrm{x}}$.

General Linear Model (GLM) was applied to compare different generations of leaves because of their small sample size and non-normal distribution. Differences among mean values were tested by post-hoc analyses using the Bonferroni's test $(\alpha=0.05)$, which was considered the most appropriate due to the limited number of samples analyzed. Bonferroni methods for multiple comparisons are extended to sequential setting and have shown to attain an approximately $50 \%$ reduction in the expected sample size compared with earlier approaches (De \& Baron 2012).

Linear regression was applied to evaluate relationships between intrinsic $\mathrm{W}_{\mathrm{i}}$ and $\mathrm{GS}$ pore length traits. Statistical analyses were not applied to young leaf attributes, because the sample number was considered insufficient to establish a clear relationship between intrinsic $\mathrm{W}_{\mathrm{i}}$ and $\mathrm{GS}$ pore length traits.

\section{Light and scanning electron microscopy (SEM)}

For light microscopy, mature leaves were clear nail polish parallel to the midrib, from the basal to apical position, and on both adaxial and abaxial surfaces. All impressions used to produce impressions, prepared with 
Tab. 1 - Number and frequency (= nGS / total number of stomata) of GS in different leaf sections and in both genotypes on the abaxial sur faces of mature leaves. The number of leaves/replicates used for each poplar clone was 20 . Frequencies were transformed as $\sqrt{ }$ x. (n.s.): not si gnificant.

\begin{tabular}{|c|c|c|c|c|c|c|c|}
\hline \multirow{2}{*}{ Genotype } & \multirow{2}{*}{ Parameter } & \multicolumn{3}{|c|}{ GS counts } & \multicolumn{3}{|c|}{ GS frequency } \\
\hline & & Apical & Medium & Basal & Apical & Medium & Basal \\
\hline \multirow[t]{2}{*}{ Poli } & Mean & 1.29 & 1.00 & 1.05 & 0.08 & 0.06 & 0.07 \\
\hline & Std. Err. & 0.18 & 0.14 & 0.19 & 0.01 & 0.01 & 0.01 \\
\hline \multirow[t]{2}{*}{$58-861$} & Mean & 1.45 & 1.20 & 1.10 & 0.08 & 0.06 & 0.06 \\
\hline & Std. Err. & 0.15 & 0.19 & 0.16 & 0.01 & 0.01 & 0.01 \\
\hline- & p-value & n.s. & n.s. & n.s. & n.s. & n.s. & n.s. \\
\hline
\end{tabular}

were fixed on glass slides, and examined under a Leica DM4000B light microscope connected to a Leica DFC420 camera at 200x magnification. Leica Application Suite (LAS) software was used to analyze images. Three sampling areas (apical, medium, and basal; $126588 \mu^{2}$ each) were randomly chosen from every slide sample for microscopic observations. Pore length and giant and normal stomata were studied on the abaxial surface of mature leaves. The absence of a cuticular ridge on the adaxial surface impressions resulted in unreliable data for GS statistical analyses on this surface.

To identify qualitative differences in stomata morphology during leaf development, further observations were performed on three categories of leaves: (i) early $(\sim 2.3 \mathrm{~cm}$ long in Poli and $\sim 2.5 \mathrm{~cm}$ long in 58-861); (ii) young $(\sim 4.8 \mathrm{~cm}$ long in Poli and $\sim 5.6 \mathrm{~cm}$ long in 58-861); and (iii) mature $(\sim 6.00 \mathrm{~cm}$ long in Poli and $\sim 10.00 \mathrm{~cm}$ long in 58-861). Each leaf developmental stage from each genotype was used to make impressions prepared with clear nail polish parallel to the midrib for light microscopy.

For SEM, samples from early, young, and mature Poli and 58-861 leaves were preserved in 1:1 $\mathrm{H}_{2} \mathrm{O}$ :ethyl alcohol at $4{ }^{\circ} \mathrm{C}$. Specimens were dehydrated in an ethanol series, critical-point dried in liquid $\mathrm{CO}_{2}$, and coated with $30 \mathrm{~nm}$ of gold. Specimens were subsequently observed under a FEI-Quantas 200 ESEM, at the CISME center of the Università degli Studi di Napoli "Federico II'. Stomatal types were classified according to Carpenter (2005) and Metcalfe \& Chalk (1979).

\section{Results and discussion}

\section{Observations from light and SEM \\ microscopy}

Large stomata, approximately $40 \mu \mathrm{m}$ in length, with anomocytic type structure were surrounded by normal stomata with paracytic structure and meristemoid cells on the developing lamina in early Poli (Fig. 1A) and 58861 leaves (data not shown). Trichomes and presumed water stomata $(\sim 50 \mu \mathrm{m}$ long) were observed on adaxial surface venation in both genotypes; however only genotype Poli is reported here (Fig. 1B). In mature P. nigra leaves, GS with anomocytic structure were surrounded by normal stomata 20 to $30 \mu \mathrm{m}$ long with paracytic structure (Fig. 1C, F). Initiation of normal stomata might continue on adaxial and abaxial surfaces, until the leaf has reached approximately $60 \%$ of its final size.

A progressive decrease in stomata length (from $\sim 40 \mu \mathrm{m}$ in GS to $\sim 20 \mu \mathrm{m}$ in normal stomata) was observed in subsequent divisions, with a concomitant transition from anomocytic to paracytic structure. The sequence of events in stomatal development
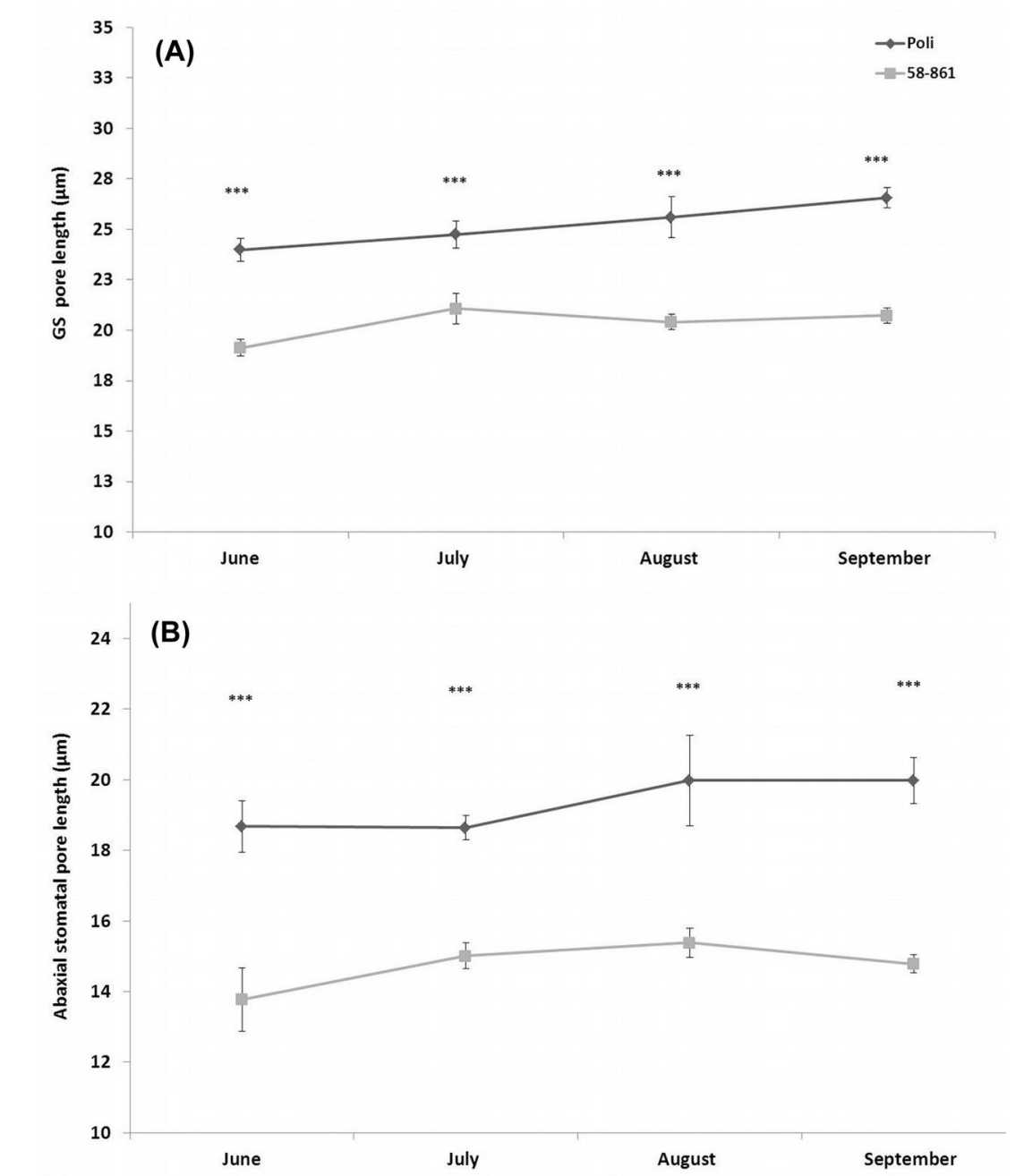

Fig. 2 - Pore length of stomata on the abaxial surface in a mature leaf. (A): Giant stomata; (B): ordinary stomata. The number of leaves/replicates used for each poplar clone was 20 . $(* * *): P \leq 0.001$ and pattern formation during the early stages of leaf development observed in P. nigra genotypes were similar to developmental stages demonstrated in A. thaliana (Von Groll \& Altmann 2001, Bergmann \& Sack 2007, Delgado et al. 2011), and in early divergent angiosperms (Rudall \& Knowles 2013). The distinct leaf stomatal pattern likely arose from GS that developed early in leaf ontogenesis, forming anomocytic stomata in primary lineages, and corresponding smaller stomata with paracytic structures in satellite li-

.




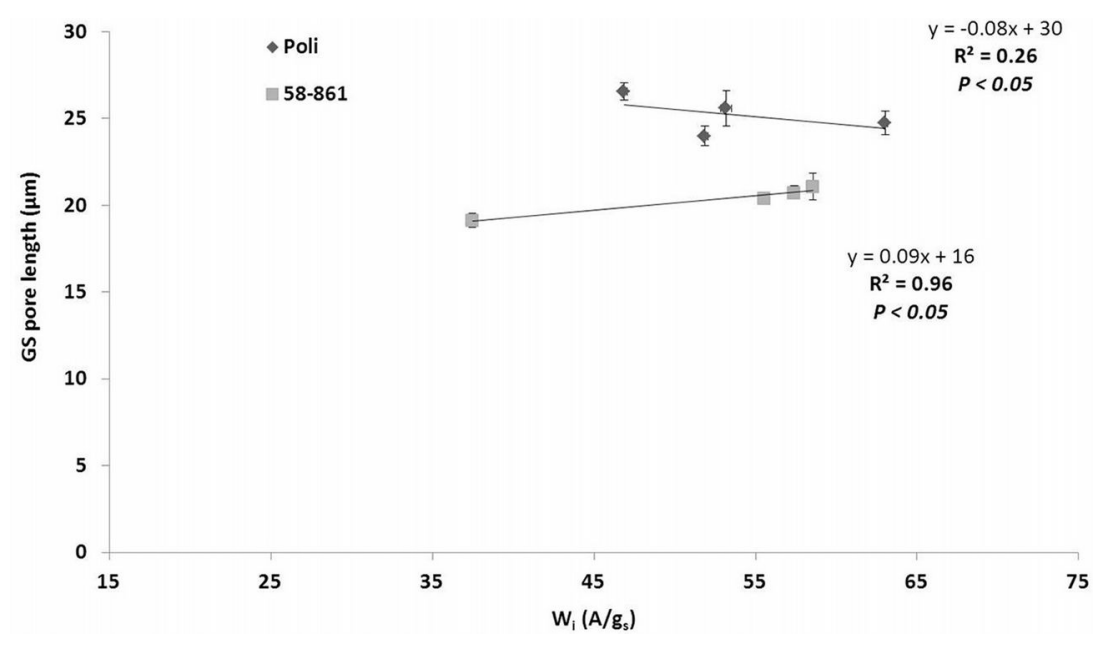

Fig. 3 - Relationships between mean size of giant stomata on abaxial surface and intrinsic WUE $\left(\mathrm{W}_{\mathrm{i}}=A / g_{\mathrm{s}}\right)$ during growing season; mean values are referred to each month of the season. $(A)$ : assimilation $\left(\mu \mathrm{mol} \mathrm{CO} \mathrm{Cm}^{-2} \mathrm{~s}^{-1}\right) ;\left(g_{\mathrm{s}}\right)$ : stomatal conductance $\left(\mathrm{mol} \mathrm{H}_{2} \mathrm{O} \mathrm{m}^{-2} \mathrm{~s}^{-1}\right)$.

neages (Von Groll \& Altmann 2001, Casson \& Gray 2008).

In mature genotype Poli leaves, the wax cover was visible, and GS were occasionally covered by wax (Fig. 1C, D). In contrast, wax plugs frequently occluded GS in mature 58-861 leaves (Fig. 1E, F).

\section{Mature leaves during growing season (light microscopy)}

Results showed Poli compared with the genotype 58-861 generally exhibited longer GS (Fig. 2A); these length differences between genotypes were also maintained in ordinary stomata, and observed throughout the growing season (Fig. 2B).

However, significant differences were not detected in GS number and frequency (= number of GS/total number of stomata) in the three leaf sections examined (apical, medium, basal) from both $P$. nigra genotypes (Tab. 1).

Different sized stomata ( 40 to $\sim 20 \mu \mathrm{m})$ were present on the adaxial and abaxial leaf sides. However, due to the absence of cuticular ridges, stomata were typically associated with GS on impressions obtained from adaxial surfaces. Therefore, statistical analyses would be unreliable if applied to GS on the adaxial surfaces. However, regression analysis performed on abaxial surfaces showed a significant relationship between GS size and $\mathrm{W}_{\mathrm{i}}$ (assimilation / stomatal conductance), with high prediction accuracy in 58$861\left(\mathrm{R}^{2}=0.96\right)$ but not in Poli $\left(\mathrm{R}^{2}=0.26\right.$ Fig. 3).

Cocozza et al. (2010) characterized the northern Italy genotype 58-861 as more water efficient and drought sensitive, with larger leaves compared with Poli, and the current study confirmed these data (Fig. 3). Previous studies on the same genotypes focused on stomatal densities and length, but did not examine the distinction between ordinary and large sized stomata (Regier et al. 2009, Cocozza et al. 2010). reduction in stomata size in genotype 58861 , but only on the abaxial leaf surface when water uptake changed, with a subsequent reduction in well-watered status. In addition, the current data suggested GS size in Poli was larger than in genotype 58-861, and might explain the increased $\mathrm{W}_{\mathrm{i}}$ verified in the northern Italy poplar clone. Furthermore, GS size could be associated with the stomatal opening and closing mechanism (together with density), which cumulatively provides total leaf stomatal conductance, and more efficient water use in genotype 58-861 despite smaller stomata.

Observed stomatal characteristics did not follow seasonal changes, suggesting the attributes were favored by selection, and represent adaptive-genetic traits. This hypothesis emphasizes the role of GS as an adaptive and functional trait distinguishing different genotypes, and might serve to clarify certain physiological attributes, including WUE in $P$. nigra.

Warren \& Adams (2006) indicated leaf anatomy was the primary factor to explain WUE by measuring stable carbon isotopes. Consequently, the role of GS in leaf physiology should take a primary role in developing a greater understanding of processes, including WUE and plasticity, or seasonal acclimation (Nicotra \& Davidson 2010). In particular, drought tolerance, as reported in the larger-sized and more water use-efficient genotype 58-861, can characterize its physiology through several adaptive traits of stomata (density, pore length, structure).

A more developed wax covering on the presents another distinctive trait of the nor-
Regier et al. (2009) reported a significant abaxial leaf surface of genotype 58-861 re- thern genotype compared to the southern Poli genotype. Pearce et al. (2006) described an additional function for wax accumulation on leaf adaxial surfaces in Populus, particularly poplars adapted to warmer regions (i.e., $P$. angustifolia). The abaxial epidermal wax covering in mature leaves of genotype Poli was reported by Pearce et al. (2006). Surface roughness, caused by ridges, trichomes, or both is the chief factor limiting wetting properties of some species, such as poplar. Superficial wax plays a dominant role in affecting wetting of other taxa (Pinon et al. 2006). The wax covering in the southern genotype Poli, and wax plugs in 58-861 might be responsible for additional differences in drought tolerance between these two genotypes, which originated from distinct environments.

Finally, stomatal analysis in the Salicaceae and closely related groups could be useful in clarifying specific features of stomatal patterns, presence of large sized stomata (GS), and the possible phylogenetic origins of normal stomata relative to GS, i.e., are GS the precursors to normal stomata. The prevailing view is that stomata arose once in evolutionary history, and subsequently radiated throughout land plants. Oversized stomata could be a significant factor in land plant evolution, with implications in physiological pathways.

An increased understanding of giant stomata can be useful to industry considering the importance of stomata in a perspective of biomass production. In fact, poplar clones with high abaxial stomatal density (where giant stomata were found) showed an increased biomass production (Al Afas et al. 2006).

\section{Acknowledgements}

The authors want to thank Dr. Francesco Fabbrini and all the researchers of DIBAF Department at the University of Tuscia for their helpfulness. We are grateful to two anonymous reviewers for their helpful comments on an earlier version of the manuscript. This work was partially supported by the European Project NOVELTREE (FP7211868)

\section{References}

Al Afas N, Marron N, Ceulemans R (2006). Clonal variation in stomatal characteristics related to biomass production of 12 poplar (Populus) clones in a short rotation coppice culture. Environmental and Experimental Botany 58 (13): 279-286. - doi: 10.1016/j.envexpbot.2005.09. 003

Bergmann DC, Sack FD (2007). Stomatal development. Annual Review of Plant Biology 58: 163-181. - doi: 10.1146/annurev.arplant.58.0328 06.104023

Carpenter KJ (2005). Stomatal architecture and evolution in basal angiosperms. American Jour- 
nal of Botany 92 (10): 1595-1615. - doi: 10.3732 /ajb.92.10.1595

Casson S, Gray JE (2008). Influence of environmental factors on stomatal development. New Phytologist 178 (1): 9-23. - doi: 10.1111/j.14698137.2007.02351.x

Ceulemans R, Impens I, Imler R (1988). Stomatal conductance and stomatal behavior in Populus clones and hybrids. Canadian Journal of Botany 66 (7): 1404-1414. - doi: 10.1139/b88-196

Cocozza C, Cherubini P, Regier N, Saurer M, Frey B, Tognetti R (2010). Early effects of water deficit on two parental clones of Populus nigra grown under different environmental conditions. Functional Plant Biology 37 (3): 244-254. - doi 10.1071/FP09156

De SK, Baron M (2012). Sequential Bonferroni methods for multiple hypothesis testing with strong control of familywise error rates I and II. Sequential Analysis 31 (2): 238-262.

Di Baccio D, Minocci A, Sebastiani L (2010). Leaf structural modifications in Populus $x \mathrm{eu}$ ramericana subjected to $\mathrm{Zn}$ excess. Biologia Plantarum 54 (3): 502-508. - doi: 10.1007/s1053 5-010-0088-x

Delgado D, Alonso-Bianco C, Fenoll C, Mena M (2011). Natural variation in stomatal abundance of Arabidopsis thaliana includes cryptic diversity for different developmental processes. Annals of Botany 107 (8): 1247-1258. - doi: 10.1093/aob/ mcr060

Erickson RO, Michelini FJ (1957). The plastochron index. American Journal of Botany 44: 297-305. - doi: 10.2307/2438380

Hermle S, Vollenweider P, Gunthardt-Goerg MS, Mcquattie CJ, Matyssek R (2007). Leaf responsiveness of Populus tremula and Salix viminalis to soil contaminated with heavy metals and acidic rainwater. Tree Physiology 27 (11): 1517 1531. - doi: 10.1093/treephys/27.11.1517

Jaime R, Serichol C, Alcántara JM, Rey PJ (2014). Differences in gas exchange contribute to habitat differentiation in Iberian columbines from contrasting light and water environments. Plant Biology 16 (2): 354-364. - doi: 10.1111/ plb.12064

Jansson S, Douglas CJ (2007). Populus: a model system for plant biology. Annual Review of Plant Biology 58 (1): 435-458. - doi: 10.1146/ annurev.arplant.58.032806.103956

Kauter D, Lewandowsky I, Claupein W (2003).
Quantity and quality of harvestable biomass from Populus short rotation coppice for solid fuel use'a review of the physiological basis and management influences. Biomass and Bioenergy 24 (6): 411-427. - doi: 10.1016/S0961-9534(02) 00177-0

Marron N, Maury S, Rinaldi C, Brignolas F (2006). Impact of drought and leaf development stage on enzymatic antioxidant system of two Populus deltoides $\times$ nigra clones. Annals of Forest Science 63 (3): 323-327. - doi: 10.1051/forest:2006012

Metcalfe CR, Chalk L (1979). Anatomy of the dicotyledons. Clarendon Press, Oxford, UK, vol. 1, pp. 276.

Nicotra AB, Davidson A (2010). Adaptive phenotypic plasticity and plant water use. Functional Plant Biology 37 (2): 117-127. - doi: 10.1071/ FP09139

Pautov AA (2009). Role of the morphogenetic correlations in the origin of heterostomatal structure. Botanicheskii Zhurnal 94: 785-792. [online] URL: http://www.cabdirect.org/abstracts/ 20093282486.html

Pearce DW, Millard S, Bray DF, Rood SB (2006). Stomatal characteristics of riparian poplar species in a semi-arid environment. Tree Physiology 26 (2): 211-218. - doi: 10.1093/treephys/26.2. 211

Pinon J, Frey P, Husson C (2006). Wettability of poplar leaves influences dew formation and infection by Melampsora larici-populina. Plant Disease 90 (2): 177-184. - doi: 10.1094/PD-900177

Radoglou KM, Jarvis PG (1990). Effect of $\mathrm{CO}_{2}$ enrichment on four poplar clones. II. Leaf surface properties. Annal of Botany 65: 627-632. [online] URL: http://aob.oxfordjournals.org/content/65/6/627.short

Regier N, Streb S, Cocozza C, Schaub M, Cherubini P, Zeeman SC, Frey B (2009). Drought tolerance of two black poplar (Populus nigra L.) clones: contribution of carbohydrates and oxidative stress defence. Plant, Cell and Environment 32 (12): 1724-1736. - doi: 10.1111/j.1365-3040. 2009.02030.x

Reich PB (1984). Leaf stomatal density and diffusive conductance in three amphistomatous hybrid poplar cultivars. New Phytologist 98 (2): 231-239. - doi: 10.1111/j.1469-8137.1984.tb02 $733 . x$
Rudall PJ, Knowles EVW (2013). Ultrastructure of stomatal development in early-divergent angiosperms reveals contrasting patterning and prepatterning. Annals of Botany 111: 1031-1043. doi: $10.1093 / \mathrm{aob} / \operatorname{mct} 169$

Rundgren M, Beerling D (1999). A holocene $\mathrm{CO}_{2}$ record from the stomatal index of subfossil Salix herbacea L. leaves from northern Sweden. The Holocene 9: 509-513. - doi: 10.1191/095968399 677717287

Sebastiani L, Scebba F, Tognetti R (2004). Heavy metal accumulation and growth responses in poplar clones Eridano (Populus deltoides $\times$ maximowiczii) and $\mathrm{I}-214(P . \times$ euramericana $)$ exposed to industrial waste. Environmental and Experimental Botany 52 (1): 79-88. - doi: 10.1016/j.envexpbot.2004.01.003

Shiraishi M, Matsumoto K, Nagatani T, Suzuki R, Shigemasu A, Kyaw T (1975). External features of floral and foliar organs of Satsuma Mandarin (Citrus unshiu Marc.) observed by scanning electron microscopy. Journal of the Japanese Society for Horticultural Science 44 (2): 107-121. doi: 10.2503/jjshs.44.107

Sitholey RV, Pandey YN (1971). Giant stomata. Annals of Botany 35: 641-642. [online] URL: http://aob.oxfordjournals.org/content/35/3/641.s hort

Stace CA (1965). Cuticular studies as an aid to plant taxonomy. Bull Br Mus Nat Hist 4: 1-78.

Von Groll U, Altmann T (2001). Stomatal cell biology. Current Opinion in Plant Biology 4 (6): 555-560. - doi: 10.1016/S1369-5266(00)002156

Warren CR, Adams MA (2006). Internal conductance does not scale with photosynthetic capacity: implications for carbon isotope discrimination and the economics of water and nitrogen use in photosynthesis. Plant, Cell and Environment 29 (2): 192-201. - doi: 10.1111/j.1365-3040. 2005.01412.x

Woo SY (2010). Epidermal leaf characteristics and seasonal changes net photosynthesis of five Populus. African Journal of Biotechnology 9 (10): 1455-1458. [online] URL: http://www.ajol.info/index.php/ajb/article/view/78319 Woodward FI, Lake JA, Quick WP (2002). Stomatal development and $\mathrm{CO}_{2}$ : ecological consequences. New Phytologist 153 (3): 477-484. doi: 10.1046/j.0028-646X.2001.00338.x 